\title{
Hybridization and backcrossing between transgenic oilseed rape and two related weed species under field conditions
} \author{
Arthur K. WEISSINGER ${ }^{1}$ and C. Neal STEWART Jr. ${ }^{2 *}$ \\ ${ }^{1}$ Crop Science Department, North Carolina State University, Raleigh, NC, USA \\ ${ }^{2}$ Department of Plant Sciences, University of Tennessee, Knoxville, TN, USA \\ ${ }^{3}$ National Water Research Institute, Environment Canada, Saskatoon, SK, Canada \\ ${ }^{4}$ Agriculture and Agri-food Canada, Ottawa, Ontario, Canada \\ ${ }^{5}$ Georgia Experiment Station, University of Georgia, Griffin, GA, USA
}

Matthew D. HALFHILL ${ }^{1,2}$, Bin ZHU ${ }^{3}$, Suzanne I. WARWICK ${ }^{4}$, Paul L. RAYMER ${ }^{5}$, Reginald J. MILLWOOD ${ }^{2}$,

Determining the frequency of crop-wild transgene flow under field conditions is a necessity for the development of regulatory strategies to manage transgenic hybrids. Gene flow of green fluorescent protein (GFP) and Bacillus thuringiensis $(B t)$ transgenes was quantified in three field experiments using eleven independent transformed Brassica napus $L$. lines and the wild relatives, $B$. rapa $L$. and Raphanus raphanistrum $L$. Under a high crop to wild relative ratio $(600: 1)$, hybridization frequency with $B$. rapa differed among the individual transformed $B$. napus lines (ranging from ca. $4 \%$ to $22 \%$ ), however, this difference could be caused by the insertion events or other factors, e.g., differences in the hybridization frequencies among the $B$. rapa plants. The average hybridization frequency over all transformed lines was close to $10 \%$. No hybridization with $R$. raphanistrum was detected. Under a lower crop to wild relative ratio (180:1), hybridization frequency with $B$. rapa was consistent among the transformed $B$. napus lines at ca. $2 \%$. Interspecific hybridization was higher when $B$. rapa occurred within the $B$. napus plot (ca. $37.2 \%$ ) compared with plot margins (ca. $5.2 \%$ ). No significant differences were detected among marginal plants grown at 1, 2, and $3 \mathrm{~m}$ from the field plot. Transgene backcrossing frequency between $B$. rapa and transgenic hybrids was determined in two field experiments in which the wild relative to transgenic hybrid ratio was 5-15 plants of $B$. rapa to 1 transgenic hybrid. As expected, ca. $50 \%$ of the seeds produced were transgenic backcrosses when the transgenic hybrid plants served as the maternal parent. When $B$. rapa plants served as the maternal parent, transgene backcrossing frequencies were $0.088 \%$ and $0.060 \%$. Results show that transgene flow from many independent transformed lines of $B$. napus to $B$. rapa can occur under a range of field conditions, and that transgenic hybrids have a high potential to produce transgenic seeds in backcrosses.

Keywords: transgenic oilseed rape / canola / Brassica napus / GFP / interspecific hybridization / Brassica rapa / Bacillus thuringiensis / introgression / Raphanus raphanistrum

\section{INTRODUCTION}

Hybridization between genetically modified crop varieties and their wild relatives and the transfer of transgenes conferring novel phenotypes to wild populations are concerns that must be addressed by governmental regulators of transgenic plants. The biological possibility of hybridization has been confirmed in laboratory and field experiments for several crop species, and future research should determine the frequency of hybridization and backcross- ing under a wide range of field conditions for particular transgenic varieties in order to determine the ecological and agricultural risks of specific variety-trait combinations (Stewart et al., 2003). The potential for ecological and agricultural risks through introgression is based on the occurrence of transgenic hybrid populations. Therefore, the next logical step in assessing these risks is to determine the frequency with which these hybridizations occur.

\footnotetext{
* Corresponding author: nealstewart@utk.edu
} 
These data are needed in order to develop rational regulatory strategies for the management of transgenic hybrids (Stewart et al., 2003).

Brassica napus L. (oilseed rape) is of particular interest as a potential source for transgene escape due to several factors. $\mathrm{Ca}$. $11 \%$ of the 25 million hectares of oilseed rape produced globally is transgenic, and is even higher in certain countries, e.g., $60 \%$ of Canadian B. napus production (James, 2001; Warwick et al., 2003). The crop is predominantly selfing with outcrossing averaging $30 \%$ (reviewed in Beckie et al., 2003), forms a persistent seed bank, and produces large weedy volunteer or feral populations particularly in the first year after oilseed rape production (Légère et al., 2001; Simard et al., 2002). In areas where more than one type of herbicide-tolerant $B$. napus has been grown, multiple herbicide-tolerant volunteer individuals have arisen as the result of intraspecific hybridization (Beckie et al., 2003; Hall et al., 2000). In many areas, wild relatives such as $B$. rapa L. (bird rape, field mustard, wild turnip), Raphanus raphanistrum L. (wild radish), and Sinapis arvensis L. (wild mustard) occur in or near oilseed rape cultivation. In a recent report, Warwick et al. (2003) have demonstrated the transfer of a herbicide (glyphosate) tolerance gene from commercial fields of oilseed rape to a naturally occurring population of B. rapa in Quebec, Canada. The agronomic characteristics of oilseed rape production combined with the occurrence of sexually compatible wild relatives demonstrate the necessity to monitor oilseed rape as a potential source of transgenes to wild populations, at least until the consequences can be determined.

The introgression of transgenes into a wild species or population occurs in a step-wise fashion starting with the initial hybridization between the transgenic crop and the wild relative. The frequency of hybridization may be affected by many factors, including the transgene insertion locus within the plant (Halfhill et al., 2002), the agronomic properties of the transgenic variety, the breeding system of the wild relative, the relative compatibility of the crop and weed species, the crop to wild relative ratio, the distance between the transgenic crop and wild relative, and the environmental conditions in the field (Stewart et al., 2003). In this study, three field experiments were performed to quantify hybridization between multiple transformed oilseed rape lines and two wild relatives (B. rapa and $R$. raphanistrum) in multiple field conditions. The effect of crop frequency was determined under high and low crop to wild relative ratios. Hybridization rates within fields and at field margins were compared. Backcrossing rates of transgenic hybrids with the wild relative were quantified in two experimental loca- tions in order to determine the incidence of introgression during subsequent generations. Together, these experiments are among the first to comprehensively characterize hybridization and backcrossing frequency among different transformation events, sites, and years.

\section{RESULTS}

\section{Hybridization field experiments}

Three field level $\mathrm{F}_{1}$ hybridization experiments were conducted, one with a high crop to wild relative ratio (600:1), the second with a lower crop to wild relative ratio (180:1). A third experiment compared within field and field margin hybridization rates. Two backcrossing experiments were performed with a wild relative to transgenic hybrid ratio of 5-15 $\mathrm{B}$. rapa plants to 1 transgenic hybrid.

\section{High Brassica napus to wild relative ratio (600:1)}

In this experiment, B. napus and $B$. rapa $\mathrm{CA}(\mathrm{Br} \mathrm{CA})$ germinated at expected rates, resulting in $50 \mathrm{~B}$. napus plants per $\mathrm{m}^{2}$ and $1 \mathrm{Br}$ CA plant per $6 \mathrm{~m}$-interval. Raphanus raphanistrum GA ( $R r$ GA) demonstrated variable germination rates, and resulted in fewer than $8 R r$ GA plants per plot with some 6 m-intervals lacking a $R r$ GA plant. The range of $R r$ GA plants per plot was between 2 and 5 plants (33 GA plants total). B. napus, $\mathrm{Br}$ $\mathrm{CA}$, and $\operatorname{Rr} \mathrm{GA}$ behaved as summer annuals, with $\mathrm{Br} \mathrm{CA}$ flowering first on May 10, the transformed B. napus lines flowered first on May 17 and the $\operatorname{Rr}$ GA plants on May 24. At the time of flowering, $B r$ CA plants were similar in size to B. napus, whereas the $R r$ GA plants were slightly shorter than the B. napus canopy, and had more branches, resulting in a larger aerial circumference than an average B. napus plant. Flowering among the three species overlapped for 4 weeks. $\mathrm{Br}$ CA finished flowering 5 weeks after the initial flower was recorded, while $\operatorname{Rr}$ GA continued to flower to the date of collection (June 25). The $B r$ CA plants had a well-defined period of flowering that finished prior to B. napus. This was in contrast to $R r$ GA plants that matured in stages, with mature seedpods present on flowering plants.

A total of 12388 seedlings from $\mathrm{Br}$ CA maternal plants were screened for GFP fluorescence, and the average hybridization frequency over all $\mathrm{Br} \mathrm{CA}$ seedlings analyzed was $9.66 \%$ (Tab. 1). The average number of seedlings screened per $\mathrm{Br}$ CA plant was $172 \pm 85$ ( \pm standard deviation). Hybridization rates varied with 
Hybridization and backcrossing between transgenic oilseed rape

Table 1. Field level hybridization with transgenic Brassica napus and wild relatives, B. rapa and R. raphanistrum, at a crop to wild relative ratio of 600 to 1 . Number of plants represents the number of wild relatives per plot. Number of seedlings represent the sum of all seedlings analyzed from the wild relatives grown within a $B$. napus transformed line, and the number transgenic represents the number of transgenic hybrids detected among the seedlings analyzed per transformed line. The \% hybridization $(+/$ - standard deviation) represents the average hybridization frequency per maternal wild relative plant grown within a $B$. napus transformed line. Total \% hybridization represents the hybridization frequency of the summed totals. Different letters represent significant differences among hybridization frequencies (Fisher's PLSD, $P<0.01$ ).

\begin{tabular}{|c|c|c|c|c|}
\hline \multicolumn{5}{|l|}{ Brassica rapa } \\
\hline B. napus line & No. of plants & No. of seedlings & No. transgenic & $\%$ hybridization \\
\hline GFP 1 & 8 & 1108 & 161 & $12.39 \pm 12.03(\mathrm{ab})$ \\
\hline GFP 2 & 8 & 1619 & 259 & $20.37 \pm 19.82$ (a) \\
\hline GFP 3 & 8 & 1282 & 72 & $5.82 \pm 5.30(b)$ \\
\hline GT 2 & 8 & 1585 & 297 & $17.11 \pm 13.20(\mathrm{ab})$ \\
\hline GT 3 & 8 & 958 & 84 & $7.79 \pm(a b)$ \\
\hline GT 4 & 8 & 1731 & 85 & $4.80 \pm 2.46(b)$ \\
\hline GT 5 & 4 & 162 & 44 & $22.02 \pm 17.20$ (a) \\
\hline GT 6 & 4 & 897 & 67 & $7.47 \pm 1.33(\mathrm{ab})$ \\
\hline GT 8 & 8 & 1733 & 60 & $3.97 \pm 3.15(b)$ \\
\hline GT 9 & 8 & 1313 & 68 & $5.37 \pm 6.63(b)$ \\
\hline Totals & 72 & 12388 & 1197 & 9.66 \\
\hline \multicolumn{5}{|c|}{ Raphanus raphanistrum } \\
\hline All events & 33 & 19274 & 0 & 0.00 \\
\hline
\end{tabular}

the transformed B. napus lines (Tab. 1) (ANOVA, $P<$ $0.01)$. The highest hybridization frequency was found with B. napus transformed line GT 5, with an average of $22.0 \pm 17.2 \%$, and the lowest with transformed line GT 8, with an average of $3.97 \pm 3.15 \%$. Hybridization frequencies from $\mathrm{Br} \mathrm{CA}$ grown within $B$. napus transformed lines GFP 2 and GT 5 differed significantly from transformed lines GFP 3, GT 4, GT 8, and GT 9 (Fisher's PLSD, $P<0.01$ ).

The seedlings produced from $R$. raphanistrum GA maternal plants were analyzed as above, and no hybrids were detected among the 19274 seedlings screened for the GFP phenotype (Tab. 1).

\section{Low Brassica napus to wild relative ratio (180:1)}

Dry environmental conditions after planting of the experiment led to a slightly lower than expected germination rate of 7-8 B. napus plants per $\mathrm{m}^{2}$ producing an average crop to $B$. rapa CA ratio of 180 to 1 . Both species initially flowered in early May, and flowering overlapped for over three weeks. A total of 7769 seedlings were screened for GFP fluorescence. The average number of seedlings screened per maternal $\mathrm{Br}$ CA was $95 \pm 91$. The average hybridization frequency for all seedlings analyzed was
$1.83 \%$ (Tab. 2). No significant differences in hybridization rates (transformed line means ranged from $0.08 \pm$ $0.17 \%$ to $3.24 \pm 7.73 \%$ ) were detected in the experiments with different $B$. napus transformed lines (ANOVA, $P>$ $0.05)$.

\section{Field margin experiment}

A total of 11392 seedlings were screened for GFP fluorescence, 6870 seedlings from B. rapa (Br QC-2975) grown within the $B$. napus field plot and 4522 seedlings from plants at the margin of the plot (Tab. 3). The average number of seedlings screened per maternal $\mathrm{Br}$ QC-2975 parent was $86 \pm 68$. In contrast to the two previous experiments, $B r$ QC-2975 plants in the plot were much shorter than the B. napus canopy. Within the $B$. napus plot, $\mathrm{Br}$ QC-2975 plants exhibited a wide range of hybridization frequencies, ranging from 0.0 to $100.0 \%$. The average hybridization frequency over all plants within the plot was $37.2 \pm 26.7 \%$. No significant differences were detected among plants grown across the plot (ANOVA, $P>0.05)$. The plants at the plot margin demonstrated lower hybridization frequencies, averaging $5.2 \pm 4.9 \%$ (range 0.0 to $17.1 \%$ ). No significant differences were detected with distance $(1,2,3 \mathrm{~m})$ from the plot (ANOVA, 
M.D. Halfhill et al.

Table 2. Field level hybridization with transgenic Brassica napus and a wild relative, B. rapa, at a crop to wild relative ratio of 180 to 1 . Number of seedlings screened represents the sum of all seedlings analyzed from $B$. rapa CA plants isolated within a GFP B. napus transformed line, and the number transgenic represents the number of transgenic hybrids detected among the seedlings analyzed per transformed line. The \% hybridization (+/- standard deviation) represents the average hybridization frequency per maternal B. rapa plant within each B. napus transformed line. Total \% hybridization represents the hybridization frequency of the summed totals.

\begin{tabular}{lcccc}
\hline \hline B. napus line & No. of B. rapa plants & No. of seedlings & No. transgenic & $\%$ hybridization \\
\hline GFP 1 & 14 & 3366 & 59 & $2.33 \pm 3.06$ \\
GFP 2 & 13 & 3376 & 58 & $3.24 \pm 7.73$ \\
GT 1 & 3 & 295 & 20 & $2.58 \pm 4.48$ \\
GT 5 & 3 & 446 & 4 & $1.11 \pm 0.98$ \\
GT 8 & 5 & 286 & 1 & $0.08 \pm 0.17$ \\
\hline Totals & 38 & 7769 & 142 & 1.83 \\
\hline
\end{tabular}

Table 3. Hybridization frequency between Brassica rapa QC-2975 plants grown within and at the margin of a transgenic $B$. napus field. Number of $B$. rapa plants represent the number grown at each location. Number of seedlings screened represent the sum all of seedlings analyzed from the $B$. rapa plants grown at a location, and the number transgenic represents the number of transgenic hybrids detected among the seedlings analyzed per location. The \% hybridization (+/- standard deviation) represents the average hybridization frequency per maternal B. rapa plant grown at a location. Total \% hybridization represents the hybridization frequency of the summed totals. Different letters represent significant differences between hybridization frequencies between plants within and the periphery of the field (T-test, $P<0.05$ ).

\begin{tabular}{lcccc}
\hline \hline Within field & No. of B. rapa plants & No. of seedlings & No. transgenic & $\%$ hybridization \\
\hline Within field total & 102 & 6870 & 2681 & $37.2 \pm 26.7(a)$ \\
Margin & No. of B. rapa plants & No. of seedlings & No. transgenic & $\%$ hybridization \\
\hline 1 meter & 10 & 1502 & 102 & $6.0 \pm 4.0$ \\
2 meter & 10 & 1555 & 106 & $5.8 \pm 5.5$ \\
3 meter & 9 & 1465 & 58 & $3.6 \pm 5.1$ \\
\hline Margin total & 29 & 4522 & 266 & $5.2 \pm 4.9(b)$ \\
Totals & $\mathbf{1 3 1}$ & $\mathbf{1 1 3 9 2}$ & $\mathbf{2 9 4 7}$ & $\mathbf{2 5 . 9}$ \\
\hline
\end{tabular}

$P>0.05)$. The hybridization frequencies of plants grown within the plot were significantly higher compared to those grown at the plot margin (T-test, $P<0.05$ ).

\section{Transgene backcrossing experiments}

In the transgene backcrossing experiment performed in North Carolina, several plots did not contain a transgenic GFP hybrid at the center of the plot, and were excluded from the study. Of the possible 51 plots, 16 contained a transgenic $\mathrm{F}_{1}$ or $\mathrm{BC}_{1}$ plant: plots from the same transformed $B$. napus line were combined for statistical analysis. The density of the surrounding $B$. rapa plants ranged from $5-15$ plants per $1 \mathrm{~m}^{2}$ plot. A total of 2095 seedlings from the maternal transgenic hybrid parents $\left(\mathrm{F}_{1}\right.$ and $\mathrm{BC}_{1}$ ) and 50177 seedlings from maternal $B$. rapa plants were screened for GFP fluorescence (Tab. 4). The average number of seedlings screened per transgenic hybrid and B. rapa plant was $131 \pm 89$ and $428 \pm 296$, respectively. When hybrids served as maternal parents, transgenic seed production ranged from $33.9 \pm 16.3 \%$ for $\mathrm{F}_{1} \mathrm{GT} 1$ hybrids to $62.7 \pm 13.5 \%$ for $\mathrm{F}_{1}$ GFP1 hybrids. No significant differences were detected in transgene frequency among transformed B. napus lines (ANOVA, $P>0.05$ ), and the average for all hybrids was $44.8 \%$. Transgene backcrossing frequency on maternal $B$. rapa plants was low, and ranged from an average of $0.026 \pm$ $0.001 \%$ in $\mathrm{F}_{1}$ GT 5 plots to $0.125 \pm 0.161 \%$ in $\mathrm{F}_{1}$ GT 4 plots. The average transgene backcrossing frequency on $B$. rapa plants over all transformed B. napus lines was $0.088 \%$.

In the Georgia location, 17 of the possible 30 plots contained a transgenic hybrid at the center of the plot. The density of the surrounding $B$. rapa plants ranged from 5-15 plants per $1 \mathrm{~m}^{2}$ plot. A total of 1950 seedlings from the maternal transgenic hybrid parents and 56845 
Hybridization and backcrossing between transgenic oilseed rape

Table 4. Transgene backcrossing frequency where a transgenic hybrid $\left(\mathrm{F}_{1}\right.$ or $\left.\mathrm{BC}_{1}\right)$ was surrounded by $5-15$ B. rapa plants in $1 \mathrm{~m}^{2}$ plots (Clayton, NC, USA). Seeds were collected from both the transgenic hybrid and each $B$. rapa plant within a plot. Number of seedlings represents the sum of all seedlings analyzed from the hybrids or B. rapa plants from hybrid plots, and the number transgenic represents the number of transgenic seedlings detected among the seedlings analyzed. The \% transgenic and $\%$ backcross (+/- standard deviation) represent the average transgenic frequency per maternal hybrid and $B$. rapa plant grown within a plot, respectively. Total \% transgenic and \% backross represent the transgenic frequency of the summed totals.

\begin{tabular}{|c|c|c|c|c|c|c|c|c|}
\hline & \multicolumn{4}{|c|}{ Transgenic hybrid } & \multicolumn{4}{|c|}{ Brassica rapa } \\
\hline & No. plots & No. of seedlings & No. transgenic & $\%$ transgenic & No. of plants & No. of seedlings & No. transgenic & $\%$ backcross \\
\hline $\mathrm{F}_{1}$ GFP 1 & 3 & 472 & 276 & $62.7 \pm 13.5$ & 24 & 9336 & 7 & $0.076 \pm 0.073$ \\
\hline $\mathrm{F}_{1}$ GT 1 & 3 & 230 & 82 & $33.9 \pm 16.3$ & 18 & 8270 & 4 & $0.048 \pm 0.014$ \\
\hline $\mathrm{BC}_{1} \mathrm{GT} 1$ & 1 & 187 & 91 & 48.7 & 8 & 3710 & 2 & 0.054 \\
\hline $\mathrm{F}_{1} \mathrm{GT} 4$ & 3 & 645 & 302 & $47.6 \pm 4.8$ & 27 & 9994 & 12 & $0.125 \pm 0.161$ \\
\hline $\mathrm{BC}_{1} \mathrm{GT} 4$ & 1 & 13 & 6 & 46.2 & 2 & 1488 & 3 & 0.202 \\
\hline $\mathrm{F}_{1}$ GT 5 & 2 & 195 & 69 & $34.3 \pm 34.8$ & 17 & 7684 & 2 & $0.026 \pm 0.001$ \\
\hline $\mathrm{F}_{1}$ GT 7 & 3 & 353 & 113 & $38.3 \pm 26.2$ & 22 & 9695 & 14 & $0.115 \pm 0.081$ \\
\hline Totals & 16 & 2095 & 939 & 44.8 & 118 & 50177 & 44 & 0.088 \\
\hline
\end{tabular}

Table 5. Transgene backcrossing frequency where a transgenic hybrid $\left(\mathrm{F}_{1}\right.$ or $\left.\mathrm{BC}_{1}\right)$ was surrounded by $5-15$ B. rapa plants in $1 \mathrm{~m}^{2}$ plots (Tifton, GA, USA). Seeds were collected from both the transgenic hybrid and each $B$. rapa plant within a plot. Number of seedlings represents the sum of all seedlings analyzed from the hybrid or $B$. rapa plants from hybrid plots, and the number transgenic represents the number of transgenic seedlings detected among the seedlings analyzed. The \% transgenic and $\%$ backcross (+/- standard deviation) represent the average transgenic frequency per maternal hybrid and $B$. rapa plant grown within a plot, respectively. Total \% transgenic and \% backross represent the transgenic frequency of the summed totals.

\begin{tabular}{|c|c|c|c|c|c|c|c|c|}
\hline & \multicolumn{4}{|c|}{ Transgenic hybrid } & \multicolumn{4}{|c|}{ Brassica rapa } \\
\hline & No. plots & No. of seedlings & No. transgenic & $\%$ transgenic & No. of plants & No. of seedlings & No. transgenic & $\%$ backcross \\
\hline $\mathrm{F}_{1}$ GFP 2 & 4 & 330 & 191 & $56.0 \pm 16.5$ & 45 & 13037 & 4 & $0.039 \pm 0.060$ \\
\hline $\mathrm{F}_{1}$ GT 3 & 5 & 1064 & 520 & $49.8 \pm 9.0$ & 45 & 19470 & 22 & $0.121 \pm 0.091$ \\
\hline $\mathrm{BC}_{1}$ GT 3 & 3 & 186 & 85 & $46.0 \pm 6.9$ & 32 & 9106 & 2 & $0.024 \pm 0.041$ \\
\hline $\mathrm{F}_{1}$ GT 8 & 4 & 342 & 176 & $51.0 \pm 2.1$ & 51 & 11832 & 6 & $0.057 \pm 0.071$ \\
\hline $\mathrm{BC}_{1}$ GT 8 & 1 & 28 & 11 & 39.3 & 9 & 3400 & 0 & 0.000 \\
\hline Totals & 17 & 1950 & 983 & 50.4 & 182 & 56845 & 34 & 0.060 \\
\hline
\end{tabular}

seedlings from maternal $B$. rapa plants were screened for GFP fluorescence (Tab. 5). The average number of seedlings screened per each transgenic hybrid and $B$. rapa plant was $114 \pm 76$ and $327 \pm 199$, respectively. Seed germination rate was classified as high for all maternal plants by visual assay. The $\mathrm{F}_{1}$ or $\mathrm{BC}_{1}$ transgenic maternal parents produced transgenic seeds at frequencies ranging from $39.3 \%\left(\mathrm{BC}_{1} \mathrm{GT} 8\right)$ to $56.0 \pm 16.5 \%\left(\mathrm{~F}_{1} \mathrm{GFP} 2\right)$ with an average of $50.4 \%$ over all hybrids, and no significant differences were detected between transformed $B$. napus lines (ANOVA, $P>0.05$ ). The backcross frequency from transgenic hybrids to surrounding $B$. rapa plants within each $1 \mathrm{~m}^{2}$ plot was low, ranging from $0 \%\left(\mathrm{BC}_{1} \mathrm{GT} 8\right)$ to $0.121 \pm 0.091 \%\left(\mathrm{~F}_{1}\right.$ GT 3$)$ with an average transgene backcrossing frequency of $0.060 \%$ over all seeds produced on $B$. rapa plants.

\section{DISCUSSION}

From this report, transgene flow has been documented among ten independent lines of transformed B. napus and $B$. rapa under field conditions. Several studies have shown that hybridization between oilseed rape and $B$. rapa (AA, $2 \mathrm{n}=20$ ) occurs under field conditions and results in the production of hybrid populations (Halfhill et al., 2002; Hansen et al., 2001; Jorgensen and Anderson, 1994; Landbo et al., 1996; Mikkelsen et al., 1996; 
Warwick et al., 2003). Hybridization occurs at a range of frequencies based on the ratio of parental crop species to the wild relative, and has been shown to be as high as 93\% when single maternal B. rapa plants were widely dispersed in oilseed rape fields (Jorgensen and Anderson 1994). Transgenic $B t$ oilseed rape varieties have been shown to hybridize with $B$. rapa under field conditions, and the frequency of hybridization was reported to range from 1 to $17 \%$ based on the transgenic variety (Halfhill et al., 2002). This research expands on the past experiments, by using multiple independent transformed lines under several experimental conditions and locations. With relatively high hybridization frequencies observed in these experiments, transgenic hybrids have the potential to be produced when these parental species occur in close proximity. Future research must examine the establishment capacity for transgenic hybrids produced under agricultural settings.

In the high B. napus to $B$. rapa ratio experiment, the variations in hybridization frequencies between transformed $B$. napus lines may be the result of the agronomic characteristics of the transformed oilseed rape line (e.g., pollen fertility and flowering time), interplant variability in the B. rapa populations, and differences in environment. Upcoming research will characterize the agronomic characteristics of the transformed B. napus lines under field conditions, in order to describe what factors may have led to differential hybridization rates. There could be maternal variation in fertility among individual $B$. rapa plants in a single accession, and transgenic hybrid output could vary among wild relative individuals based on maternal factors. This hypothetical variation was outside the scope of this study. Future work should characterize the variation in hybridization potential of the $B$. rapa accessions, in order to clarify this potentially confounding factor. The low crop to wild relative ratio experiment illustrated that crop frequency may affect hybridization frequency, and lower hybridization frequencies with $B$. rapa may be observed when lower frequency stands occur, such as the case when transgenic B. napus volunteers are the predominant transgenic plant, as opposed to a high density crop stand in a production field. Year-to-year variation, site-to-site variation, and differences in plot design should not be overlooked as factors that could have contributed to the different hybridization frequencies between high and low crop frequencies. In this study, it is conceivable that differential seed dormancy between hybrid and B. rapa seeds may have led to an overestimation in hybridization frequency over all transformed lines (e.g., Landbo and Jorgensen, 1997). Overall, hybridization between transgenic
B. napus and B. rapa occurred over a wide range of experimental conditions.

Hybridization between GFP B. napus and $R$. raphanistrum was not detected in our study. Although several reports have documented the occurrence of this interspecific hybridization event (Baranger et al., 1995; Chèvre et al., 2000; Darmency et al., 1998; Eber et al., 1994; Rieger et al., 2001; Warwick et al., 2003), the frequency of hybridization was always low. In Australia, gene flow between $B$. napus and imidazolinone-resistant $R$. raphanistrum was detected at a low rate $\left(<4 \times 10^{-8}\right)$ and only when the $B$. napus served as the maternal parent (Reiger et al., 2001). In France, Chèvre et al. (2000) estimated that the hybridization frequency was between $10^{-7}$ and $10^{-5}$. In a recent report, Warwick et al. (2003) found a single herbicide (glyphosate) tolerant $F_{1}$ hybrid out of $c a .35000$ germinated seedlings (i.e., rate of $3 \times 10^{-5}$ ). The utility of GFP for detecting very low frequency events (rarer than 1 in $10^{6}$ ) is limited, because the GFP system requires a visual assay of each individual for accurate screening. Other systems, such as herbicide tolerance screening, may be more effective when very large numbers of plants must be analyzed.

The transgene backcrossing frequencies presented in this study are some of the first reported describing the transgene movement from multiple transformed lines of transgenic hybrids to wild relatives. The low rates of transgene backcrossing found in the current study from transgenic hybrids to maternal $B$. rapa plants were similar to the finding of Pertl et al. (2002) using transgenic $F_{1}$ hybrids from a single glufosinate-tolerant oilseed rape line. In our study, the expected rate of transgene backcrossing was calculated to be $2.5 \%$ (1 of 40 seeds) based on the following factors. In our field experiments, the ratio of hybrid to wild relative was on average 1 to 10 (10\% transgene backcrossing expected initially). Warwick et al. (2003) demonstrated that hybrids have ca. $50 \%$ pollen fertility ( $10 \%$ divided by 2 , resulting in $5 \%$ ). Hybrid plants were hemizygous for the transgene, and therefore $50 \%$ of its pollen should be transgenic (5\% divided by 2 , resulting in $2.5 \%$ ). This may be an overestimate in some transformed lines, if the transgene is located on one of the chromosomes of the $\mathrm{C}$ genome of the B. napus line. Although this is a simplified calculation method that excludes potential factors such as flower number per parental genotype, percentage of pollen fertility, and percentage seed abortion, it does allow for conceptual comparisons between an idealized transgene backcrossing frequency and the actual frequency found under field conditions. The experimentally determined transgene backcrossing frequency of $0.074 \%$ 
Hybridization and backcrossing between transgenic oilseed rape

( 1 of 1350 seeds) over both experiments was much lower than the expected rate of $2.5 \%$. Future studies will be performed to characterize this phenomenon. Possible explanations that might be hypothesized include slight differences in flowering time, female reproductive variability in the $B$. rapa population, variation in hybrid pollen fitness, and differential fertilization success (pollen competition) between $B$. rapa and hybrid pollen within $B$. rapa stigmas. Hauser et al. (1997) analyzed pollen competition between $B$. napus and $B$. rapa pollen on both maternal stigmas under greenhouse conditions, and found no significant differences between pollen types when $B$. rapa was the female parent.

Transgenic seed production with the hybrid as the maternal parent was at the expected ca. 50\% level. In this case, if the single transgenic hybrid was self-incompatible (sporophytic self-incompatibility acquired from the $B$. rapa parent), all pollination should be from the surrounding $B$. rapa plants. The hybrid produces $50 \%$ transgenic ova, and therefore the expected number of transgenic progeny should be 50\%. Mikkelsen et al. (1996) performed similar backcrossing experiments, and also found backcrossing with BASTA-tolerant $F_{1}$ hybrids as the maternal parent when surrounded by $B$. rapa plants. From these experiments, transgenic hybrids have a high potential to generate transgenic progeny as the maternal parent, and transgenic hybrids should be the focus of governmental regulatory strategies to manage transgenic populations under field conditions.

\section{MATERIALS AND METHODS}

\section{Plant material}

Primary transgenic plants $\left(\mathrm{T}_{0}\right)$ of oilseed rape (Brassica napus $\mathrm{cv}$. Westar) transformed with a plasmid containing GFP (Aequorea victoria, mGFP5er variant, Haseloff et al., 1997) and Bt (Bacillus thuringiensis, synthetic $B t$ cry $1 A c$ ) genes received the label "GT", and plants transformed with a plasmid containing only GFP were "GFP" (Halfhill et al., 2001). A transformed line was defined as the progeny of a single, independently transformed plant recovered from tissue culture. Nine homozygous $\mathrm{T}_{3}$ GT (GT 1-9) transformed lines and three homozygous $\mathrm{T}_{3}$ GFP (GFP 1-3) transformed lines were used as model transgenic crop varieties. Two weed species were selected as model wild relatives: $B$. rapa and Raphanus raphanistrum. Three accessions of $B$. rapa ( $B r$ CA from Irvine, CA, USA (33 40’ N 117 49’ W), courtesy of Art Weis; $B r$ QC-2974 from Milby, QC, Canada (45 $\left.19^{\prime} \mathrm{N} 71^{\circ} 49^{\prime} \mathrm{W}\right)$ and $\mathrm{Br}$ QC-2975 from
Waterville, QC, Canada ( $\left.45^{\circ} 16^{\prime} \mathrm{N} 71^{\circ} 54^{\prime} \mathrm{W}\right)$ germplasm collection AAFC-ECORC, Ottawa) and one accession of $R$. raphanistrum ( $R r$ GA from Leesburg, GA, USA $\left(31^{\circ} 44^{\prime} \mathrm{N} 84^{\circ} 10^{\prime} \mathrm{W}\right)$, collected as separated seed from a rye seed cleaning facility), were used in these field experiments.

\section{High Brassica napus to wild relative ratio (600:1)}

A GFP B. napus field experiment was conducted at the Central Crops Research Station, Clayton, NC, USA $\left(35^{\circ} 39^{\prime} \mathrm{N} 78^{\circ} 27^{\prime} \mathrm{W}\right)$ in the spring of 2001 with a $B$. napus to wild relative ratio of 600 to 1 . Seeds of eight lines of transformed GFP B. napus (GT 2-4, GT 8-9, and GFP 1-3) were hand sown in $2 \mathrm{~m} \times 48 \mathrm{~m}$ plots, one transformed line per plot ( 8 plots). Transformed lines GT5 and GT 6 had a limited number of seeds available at the time of sowing, and therefore were sown in plots of $2 \mathrm{~m} \times 24 \mathrm{~m}$ ( 2 plots, 10 plots total combining all transformed lines). The seeds were randomly scattered with a density of 100 seeds per $\mathrm{m}^{2}$ for a final stand density of 50 plants per $\mathrm{m}^{2}(50 \%$ expected germination rate). At the time of B. napus planting (March 27, 2001), $16 B$. rapa $\mathrm{CA}$ and $R$. raphanistrum GA seeds were sown at alternating 3-meter intervals in the center of each plot (6-meter interval between individuals of the same species). After germination, the $B$. rapa and $R$. raphanistrum plants were culled to 1 plant per 6-meter interval, resulting in 8 wild relatives per species and per plot. Time of flowering (first flower on any plant of the species) was recorded for B. napus, B. rapa, and $R$. raphanistrum. At maturity, seeds from each wild relative were collected individually in paper bags, cleaned, and placed in a $4^{\circ} \mathrm{C}$ refrigerator between $2-4$ months. B. rapa seeds and $R$. raphanistrum pod segments containing the seed were sown in soil-mix in $4 \mathrm{~cm} \times 6 \mathrm{~cm}$ cells (5-6 seeds per cell) in trays $(26 \mathrm{~cm} \times 56 \mathrm{~cm}, 48$ cells per tray, 240-288 seeds per tray) under greenhouse conditions. For each $B$. rapa maternal plant, all seeds were sown if the plant produced less than 576 seeds, and if the plant produced more than 576 seeds, 576 seeds (2 flats) were sown. All $R$. raphanistrum pod segments from each maternal parent were sown. Seed germination rate was noted by informal visual observation, and little seed dormancy was noted. All seedlings were screened at the cotyledon stage by visual, qualitative assay for GFP fluorescence using a hand-held, long-wave ultraviolet light (Spectroline high-intensity long-wave UV lamp, BIB-150P model, $350 \mathrm{~nm}$ ). Hybridization rates were calculated by observing the number of seedlings that were green fluorescent (transgenic) compared to the total 
number of germinated seedlings as described by Halfhill et al. (2001). GFP screening has proven to be robust for this system (Halfhill et al., 2003; Richards et al., 2003).

\section{Low Brassica napus to wild relative ratio (180:1)}

A GFP B. napus field experiment was conducted at the Upper Piedmont Research Station in Reidsville, NC, USA ( $36^{\circ} 20^{\prime} \mathrm{N} 79^{\circ} 39^{\prime} \mathrm{W}$ ) in the spring of 2000 with an initial crop to wild relative ratio of $250: 1$. Five homozygous transformed B. napus lines (GT 1, 5, 8 and GFP 1-2) were planted in $5 \mathrm{~m} \times 5 \mathrm{~m}$ plots (one line per plot). Seed availability varied between the transformed lines, and the number of plots per transformed line was dependant on seed availability (GT 1, 3 plots; GT 5, 3 plots; GT 8, 5 plots; GFP 1, 14 plots; GFP 2, 13 plots; 38 plots in total). Each $25 \mathrm{~m}^{2}$ plot was randomly planted within the field, and the plots were separated by a $5 \mathrm{~m}$ boundary on all sides. B. napus seeds were hand-planted in early March 2000 at a rate of 20 seeds per $\mathrm{m}^{2}$ for a final stand density of 10 plants per $\mathrm{m}^{2}(50 \%$ expected germination rate). Sixteen $B$. rapa $C A$ seeds were planted at the center of each plot at the same time as the B. napus lines, and were later culled to 1 wild relative plant per plot. At maturity, seeds were harvested individually in paper bags in early June from the $B$. rapa CA plants, cleaned, and stored at $4^{\circ} \mathrm{C}$ between 2-4 months. Seeds were sown in trays of soil-mix (as above) in controlled environmental chambers. Seedlings were screened at the cotyledon stage by visual, qualitative assay for GFP fluorescence. Hybridization rates were calculated in the same fashion as above.

\section{Field margin experiment}

A GFP B. napus field experiment was performed at the Central Experimental Farm, AAFC-ECORC, Ottawa, Canada $\left(45^{\circ} 23^{\prime} \mathrm{N} 75^{\circ} 43^{\prime} \mathrm{W}\right)$ in 2001 . In a $10 \mathrm{~m} \times 10 \mathrm{~m}$ field plot $\left(100 \mathrm{~m}^{2}\right)$, seeds of GT 9 B. napus were sown in 31 rows with the distance of $0.33 \mathrm{~m}$ between rows with a planting rate of 160 seeds per $\mathrm{m}^{2}$. Within the plot, one seed of B. rapa QC-2975 was sown or one plant transplanted starting at the $0 \mathrm{~m}$ or plot edge, with the distance of $1 \mathrm{~m}$ between rows (11 rows total) and $1 \mathrm{~m}$ apart between plants in each row (11 plants total per row). Thus, a total of 121 B. rapa plants were planted within the plot. To test the impact of distance of pollen flow on the hybridization rate at the margin of the field plot, on one side of the plot, B. rapa QC-2975 plants were planted or transplanted in rows at distances of 1,2 , and $3 \mathrm{~m}$ respectively from the edge of the plot ( 33 B. rapa plants total). B. rapa QC-2975 plants were allowed to mature in the field, and seeds of each plant harvested individually. Seeds were then cleaned, stored at $4^{\circ} \mathrm{C}$ between 2-4 months, germinated under greenhouse conditions, and screened for GFP fluorescence at the 2-3 week stage, and hybridization frequency was calculated as above.

\section{Transgene backcrossing experiments}

Transgene backcrossing frequency was quantified in two field experiments at the Central Crops Research Station, Clayton, NC, USA ( $35^{\circ} 39^{\prime} \mathrm{N} 78^{\circ} 27^{\prime} \mathrm{W}$ ) in 2000-2001, and at the Lang Research Farm, Tifton, GA, USA $\left(31^{\circ} 27^{\prime} \mathrm{N} 83^{\circ} 30^{\circ} \mathrm{W}\right)$ in 2001-2002. The fields were sown in November in each location, and were completed in May of the following year. In NC, a total of 15 different transgenic $\mathrm{F}_{1}$ hybrids from the hybridization of $B$. rapa accessions CA, QC-2974, and QC-2975 and B. napus lines GFP1, GT1, GT4, GT5, and GT7, respectively and two $\mathrm{BC}_{1}$ hybrids from $\mathrm{Br}$ CA $\times \mathrm{GT} 1$ and $\mathrm{Br}$ QC- $2974 \times$ GT4 were utilized (B. rapa served as the maternal parent in all crosses). In each $1 \mathrm{~m} \times 1 \mathrm{~m}$ plot, one transgenic $\mathrm{F}_{1}$ or $\mathrm{BC}_{1}$ hybrid was surrounded by the respective $B$. rapa parental accession. Three replicate plots from each oilseed rape line by $B$. rapa accession were planted (example: 3 CA $\times$ GT1 plots, 3 QC-2974 × GT1 plots, and 3 QC- $2975 \times$ GT1 plots) for a total of $45 F_{1}$ plots and $6 \mathrm{BC}_{1}$ plots. In $\mathrm{GA}, \mathrm{F}_{1}$ and $\mathrm{BC}_{1}$ hybrids from the cross of B. rapa $\mathrm{CA}$ and $B$. napus lines GFP2, GT3, and GT8 were planted. Five replicate plots of each $\mathrm{F}_{1}$ and $\mathrm{BC}_{1}$ hybrid type were planted (30 plots in total). Within each $1 \mathrm{~m} \times 1 \mathrm{~m}$ plot, $50 \mathrm{~B}$. rapa seeds of the parental accession were hand-planted randomly over the plot, and 16 putative transgenic hybrid seeds were hand-planted at the center of each plot in early November. After germination, transgenic hybrids were screened at night for GFP fluorescence with a hand-held UV light and culled to 1 transgenic hybrid per plot. The $B$. rapa plants were culled to 15 plants per plot, leading to a wild relative to transgenic hybrid ratio of 15 to 1 . At maturity in the following spring, the seeds of each plant (both the transgenic hybrid and B. rapa plants) were collected individually in paper bags from each plot, cleaned, and stored at $4^{\circ} \mathrm{C}$ between 2-4 months. Seeds were germinated in moist filter paper rolls (50-200 seeds per roll) and screened for GFP fluorescence. For each transgenic hybrid, 50-200 seeds (one roll) were germinated, and for each B. rapa maternal plant, a maximum of 1600 seeds (8 rolls) was germinated. Hybridization frequency was calculated as above. 
Hybridization and backcrossing between transgenic oilseed rape

\section{ACKNOWLEDGEMENTS}

We would like to thank the USDA Biotechnology Risk Assessment Grants Program for funding, Laura Hudson (UT), Stephen Burgin (NCSU), Harry Richards (UT), and Connie Sauder (AAFC-Ottawa) for technical assistance.

Received April 17, 2003; accepted December 11, 2003.

\section{REFERENCES}

Baranger A, Chèvre AM, Eber F, Renard M (1995) Effect of oilseed rape genotype on the spontaneous hybridization rate with a weedy species: and assessment of transgene dispersal. Theor. Appl. Genet. 91: 956-963

Beckie HJ, Warwick SI, Nair H, Sequin-Swartz G (2003) Gene flow in commercial fields of herbicide-resistant oilseed rape (Brassica napus). Ecol. Appl. 13: 1276-1294

Chèvre AM, Eber F, Darmency $H$, Fleury A, Picault H, Letanneur JC, Renard M (2000) Assessment of interspecific hybridization between transgenic oilseed rape and wild radish under agronomic conditions. Theor. Appl. Genet. 100: 1233-1239

Darmency H, Lefol E, Fleury A (1998) Spontaneous hybridizations between oilseed rape and wild radish. Mol. Ecol. 7: 1467-1473

Eber F, Chèvre AM, Baranger A, Vallee P, Tanguy X, Renard M (1994) Spontaneous hybridization between a male-sterile oilseed rape and two weeds. Theor. Appl. Genet. 88: $362-368$

Halfhill MD, Richards HA, Mabon SA, Stewart CN Jr. (2001) Expression of GFP and Bt transgenes in Brassica napus and hybridization and introgression with Brassica rapa. Theor. Appl. Genet. 103: 362-368

Halfhill MD, Millwood RJ, Raymer PL, Stewart CN Jr. (2002) Bt-transgenic oilseed rape hybridization with its weedy relative, Brassica rapa. Environ. Biosafety Res. 1: $19-28$

Halfhill MD, Millwood RJ, Weissinger AK, Warwick SI, Stewart CN Jr. (2003) Additive transgene expression and genetic introgression in multiple GFP transgenic crop $\times$ weed hybrid generations. Theor. Appl. Genet. 107: 1533-1540

Hall L, Topinka K, Huffman J, Davis L, Good A (2000) Pollen flow between herbicide-resistant Brassica napus is the cause of multiple-resistant B. napus volunteers. Weed Sci. 48: 688-694

Hansen LB, Siegismund HR, Jorgensen RB (2001) Introgression between oilseed rape (Brassica napus L.) and its weedy relative $B$. rapa L. in a natural population. Genet. Res. Crop Evol. 48: 621-627

Haseloff J, Siemering KR, Prasher D, Hodge S (1997) Removal of a cryptic intron and subcellular localization of green fluorescent protein are required to mark transgenic Arabidopsis plants brightly. Proc. Natl. Acad. Sci. USA 94: 2122-2127

Hauser TP, Jorgensen RB, Osttergard H (1997) Preferential exclusion of hybrids in mixed pollinations between oilseed rape (Brassica napus) and weedy B. campestris (Brassicaceae). Am. J. Bot. 84: 756-762

James C (2001) Global Review of Commercialized Transgenic Crops: 2001. ISAAA Briefs No. 24-2001 ISAAA (International Service for the Acquisition of Agri-Biotech Applications), Ithaca, NY

Jorgensen RB, Andersen B (1994) Spontaneous hybridization between oilseed rape (Brassica napus) and weedy $B$. campestris (Brassicaceae): a risk of growing genetically modified oilseed rape. Am. J. Bot. 81: 1620-1626

Landbo L, Andersen B, Jorgensen RB (1996) Natural hybridization between oilseed rape and a wild relative: hybrids among seeds from weedy $B$. campestris. Hereditas 125: 89-91

Landbo L, Jorgensen RB (1997) Brassica campestris and its hybrids with $B$. napus: implications for risk assessments of transgenic oilseed rape. Euphytica 97: 209-216

Légère A, Simard M-J, Thomas AG, Pageau D, Lajeunesse J, Warwick SI, Derksen DA (2001) Presence and persistence of volunteer oilseed rape in Canadian cropping systems. Proc. Brighton Crop Prot. Conf. - Weeds. British Crop Protection Council, Farnham, Surrey, UK, pp 143-148

Mikkelsen TR, Andersen B, Jorgensen RB (1996) The risk of crop transgene spread. Nature 380: 31

Pertl M, Hauser TP, Damgaard C, Jorgensen RB (2002) Male fitness of oilseed rape (Brassica napus), weedy B. rapa and their $\mathrm{F}_{1}$ hybrids when pollinating $B$. rapa seeds. Heredity 89: $212-218$

Richards HA, Halfhill MD, Millwood RJ, Stewart CN Jr. (2003) Quantitative GFP fluorescence as an indicator of recombinant protein synthesis in transgenic plants. Plant Cell Rep. 22: 117-121

Rieger MA, Potter TD, Preston C, Powles SB (2001) Hybridization between Brassica napus L. and Raphanus raphanistrum L. under agronomic field conditions. Theor. Appl. Genet. 103: 555-560

Simard MJ, Légère A, Pageau D, Lajeunnesse J, Warwick S (2002) The frequency and persistence of oilseed rape (Brassica napus) volunteers in Québec cropping systems. Weed Technol. 16: 433-439

Stewart CN Jr., Halfhill MD, Warwick SI (2003) Transgene introgression from genetically modified crops to their wild relatives. Nat. Rev., Genet. 4: 806-817

Warwick SI, Simard MJ, Légère A, Beckie HJ, Braun L, Zhu B, Mason P, Seguin-Swartz G, Stewart CN Jr. (2003) Hybridization between transgenic Brassica napus L. and its wild relatives: B. rapa L., Raphanus raphanistrum L., Sinapis arvensis L., and Erucastrum gallicum (Willd.) O.E. Schulz. Theor. Appl. Genet. 107: 528-539 